\title{
Tasarım Süreçlerinde Otomasyon Sistemlerinin Optimizasyonu ve Etkilerinin İncelenmesi
}

\author{
Burak Gül $^{1 *}$, Ersin Toptaş² \\ ${ }^{1 *}$ Marmara Üniversitesi, Teknoloji Fakültesi, Mekatronik Mühendisliği Bölümü, İstanbul, Türkiye, (ORCID: 0000-0043-4045-0316), burak_mkt@hotmail.com \\ ${ }^{2}$ Marmara Üniversitesi, Teknoloji Fakültesi, Mekatronik Mühendisliği Bölümü, İstanbul, Türkiye, (ORCID: 0000-0001-6667-0638), etoptas@marmara.edu.tr
}

(1st International Conference on Applied Engineering and Natural Sciences ICAENS 2021, November 1-3, 2021)

(DOI: 10.31590 /ejosat.1026372)

\begin{abstract}
ATIF/REFERENCE: Gül, B. \& Toptaş, E. (2021). Tasarım Süreçlerinde Otomasyon Sistemlerinin Optimizasyonu ve Etkilerinin
\end{abstract} İncelenmesi. Avrupa Bilim ve Teknoloji Dergisi, (28), 1534-1539.

\section{$\ddot{O} z$}

$\mathrm{Bu}$ çalışmada otomasyon hatlarının tasarım ve çalışmasına etki eden dinamik parametreler örnek bir hat üzerinde tespit ve optimize edilerek hatların verimliliğine olumlu etkileri araştırılmıştır. Otomasyon hatlarının mekanik, elektronik ve yazılımın bir arada olduğu sistemlerde kalite ve yüksek performans üretim endüstrisi tarafından istenen bir özelliktir. Bu sistemleri maksimum verimliliğe ulaştırmak için daha tasarım sürecindeyken mekanik, elektronik ve yazılımsal parametrelerin bir arada düşünülerek optimize edilmesi sistemin zaman ve maliyet açısından kazandıkları sistemin verimliliğinin artması açısından önemlidir. Bu verimliliğin artmasına yönelik örnek bir otomasyon hattı tasarımı ve optimizasyonuna yönelik bir çalışma sunulmuştur. Çalışmada farklı boylardaki şişelere kapak takan otomasyon hattı üzerinden fiziksel ve parametrik değişikliklerin üretim süreci üzerindeki etkileri araştırılmıştır. Araştırmada yerçekimi, sürtünme gibi fiziksel büyüklüklere bağlı şişe akış hızı, kapak takma silindiri hızı sanal ortamda optimize edilmiş; ayrıca sistem sanal ortamda devreye alınarak ortaya çıkan tasarım hataları tespit edilerek düzeltilmiştir. Böylelikle bir ürünün üretim sürecinde kullanılacak otomasyon hattının tasarımında mühendislik hesaplamaları, hareket analizleri, eyleyicilerin etkileri, algılama ve kontrol parametrelerinin aynı anda düşünülerek hat tasarımının tamamlanması gerektiği tezi deneysel olarak da desteklenmiştir. Örnek sistemde çevrim süresinin ve tasarım süresinin kısalmasından doğan \%30’luk bir iyileştirme sağlanmıştır. Bu sunulan yaklaşımın otomotiv, gıda, kimya vb. sanayilerde insan hatasından arındırılmış ve ürün hareketlerinin önceden kestirilemediği otomasyon hatlarına sahip tüm üretim tesisleri için yeni hatların tasarımına yeni bir bakış açısı kazandırılmış olacaktır. Hatasız üretime geçirilebilen otomasyon hatlarıyla ekonomik verimliliğinin de en üst seviyelere ulaştırılmasına 1şık tutulacaktır.

Anahtar Kelimeler: Optimizasyon, Sanal devreye alma, Mekatronik konsept tasarımı, Makine dijital ikizi, Otomasyon hattı simülasyonu.

\section{Optimization of Automation Systems and Investigation of Effects in Design Processes}

\begin{abstract}
In this study, dynamic parameters affecting the design and operation of automation lines were determined and optimized on a sample line and their positive effects on the efficiency of the lines were investigated. In this study, dynamic parameters affecting the design and operation of automation lines were determined and optimized on a sample line and their positive effects on the efficiency of the lines were investigated. Quality and high performance in systems where automation lines combine mechanics, electronics and software is a feature desired by the manufacturing industry. In order to bring these systems to maximum efficiency, optimizing the mechanical, electronic and software parameters together during the design process is important in terms of increasing the efficiency of the system, which the system gains in terms of time and cost. A study on the design and optimization of an exemplary automation line to increase this efficiency is presented. In the study, the effects of physical and parametric changes on the production process were investigated through the automation line that caps bottles of different sizes. In the research, bottle flow rate and capping cylinder speed depending on physical quantities such as gravity and friction were optimized in a virtual environment; In addition, the system was commissioned in the virtual environment and the design errors that occurred were identified and corrected. Thus, the thesis that the line design should be completed by considering engineering calculations, motion analysis, the effects of actuators, sensing and control parameters at the same time in the design of the automation line to be used in the production process of a product was also supported experimentally. In the sample system, a 30\% improvement was achieved due to the shortening of the cycle time and design time. This presented approach can be applied to automotive, food, chemistry, etc. A new perspective will be gained in the design of new lines for all production facilities with automation lines, which are free from human error in industries and where product
\end{abstract}

\footnotetext{
*Sorumlu Yazar: burak mkt@hotmail.com
} 
movements cannot be predicted. With the automation lines that can be put into production without errors, it will be shed light on reaching the highest level of economic efficiency.

Keywords: Optimization, Virtual commissioning, mechatronics concept design, machine dijital twin, automation line simulation.

\section{Giriş}

Otomasyon hatları yapısı itibariyle sensörler, uyarıcılar, butonlar, motor, sürücü, pnömatik eyleyiciler gibi birçok giriş ve çıkış elemanlarından oluşmaktadır. Bu elemanların otomasyon hatları üzerindeki konum, tepki süresi, hız, hareket grafikleri gibi parametreleri değiştirilebilmekte ve kontrol edilebilmektedir. $\mathrm{Bu}$ tür yapıların ve parametrelerin mekatronik sistemlerdeki etkisi üretim sürecindeki verimliliği etkilemektedir. Aynı zamanda bu giriş çıkışları kontrol eden ve mekatronik sistemlerin kontrolünde temel taşlardan biri olan programlanabilir mantıksal denetleyici olan PLC'lerin programlanmasına yardımcı olacak algoritmaların ortaya çıkarılmasının verimliliğe olumlu etkileri vardır (Çilek, 2005).

Endüstri 4.0'ın yaygın olarak konuşulduğu ve sanayiyi etkilemeye başladığı bu yeni dönemde birçok yeni teknoloji ortaya çıkmıştır (Stock, T., \& Seliger, G., 2016). Nesnelerin interneti, akıllı fabrikalar, 3D yazıcılar, artırılmış gerçeklik, giyilebilir teknolojiler vb. bu teknolojilerden bazılarıdır (Henning, 2013). Sanal devreye alma da bu parlayan teknolojilerden biridir. Sanal devreye alma teknolojisi sayesinde tasarlanacak hattın daha az hatayla üretileceği ve tasarım sürecinin hızlanarak zamandan tasarruf edileceği düşünülmektedir. Gerçek prototiplerin kurulmasına gerek kalmadan sistemin test edilmesi sağlanarak oluşacak maliyetler ve gerekli işgücünün en aza indirileceği görüşü ortaya konmuştur (Puntel-Schmidt, P., \& Fay, A., 2015).

\subsection{Otomasyon Hatlarının Geleneksel Yöntemlerle İnşasında Yaşanılan Aksaklıklar}

Mekatronik sistemlerin birkaç disiplini barındırması ve karmaşık bir yapı oluşturması sebebiyle otomasyon hatlarının düşünceden devreye alınmasına kadar olan süreçte değişik problemlerin oluşması kuvvetle muhtemeldir. Bu tür sorunların ortaya çıkması durumunda değişik yöntemlerle sorunun çözümüne yönelik çalışılmaktadır. Fakat yapılan bu sorun çözümleri zaman kaybı ve imalat masraflarına sebep olmakta, tasarımda değişikliğe gidilmesini dahi gerektirebilmektedir.

Otomasyon hatlarının geleneksel olarak tasarlanıp devreye alınmasında, Şekil 1.1'de belirtildiği gibi hattı kuracak işletme tarafından teknik özellikler belirlenir. Sonrasında mekanik ve elektriksel tasarım ayrı ayrı çalışılıp sistem ortaya çıkarılmaktadır. Otomasyon sisteminin çalışması gerçek makine veya üretim hattında test edilmektedir. $\mathrm{Bu}$ sistemlerin gün geçtikçe daha karmaşık hale gelmesiyle sistemlerin tasarlanması, prototipinin oluşturulup test edilmesi gibi aşamalar oldukça uzun vakit alabilmektedir. Ayrıca uygulamada önemli sorunlara yol açabilmek. Bu sorunlar, artık birçok firma tarafindan bilinmekte ve çözüm için gerekli değişiklikler uygulamaya konulmaktadır. En önemli sorun, mekanik ve elektrik/kontrol tasarımı bölümünün öncelikle fiziki anlamda ayrı olmasıdır. Bu durum ekiplerin bilgi ve deneyim birikimlerini ortak kullanarak aynı tasarım konusunda beraber çalışarak sinerji yaratma olanağını engellemektedir. Fiziki olarak ayrı mekânlarda görev yapan ekipler arasında olması gereken iletişim ve ekip çalışma anlayışı zayıf olabilmektedir. Teknik konularda da bütünleşmiş bilgi eksikliği nedeniyle birbirlerini anlamakta zorluk çeken ekipler, tasarımın hem mekanik hem de kontrol tekniği açısından fonksiyonel, ekonomik ve verimli bir çözüme yönlendirilmesinde etkin bir çalışma yapamamaktadır (Karcı, 2001).

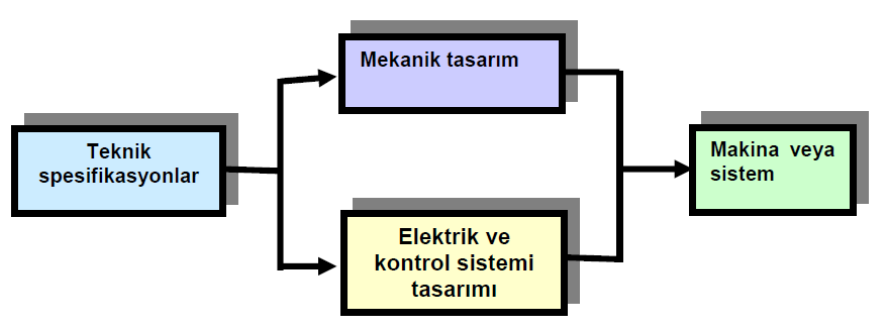

Şekil 1.1: Geleneksel Mekatronik Sistem Tasarım Aşamaları

Otomasyon sistemlerinin tasarlanmasında yapılan küçük bir hata sistemin çalışmasına büyük zararlar verebilmektedir. Bu durum üretici firmalar için zaman kaybına ve maddi zarara yol açmaktadır. Test aşamasında otomasyon sisteminde kullanılan çeşitli sensörler, eyleyici vb. elemanların sistem üzerinde nereye konulursa daha verimli çalışacağını keşfetmek uzun yılları alan tecrübe ve bilgi birikimiyle gerçekleşebilmektedir (Groover, 2001). Tanımlanamayan bir hata için hata ile ilgili maliyetler Şekil 1.2'de gösterildiği gibi tasarım sürecinin her safhasında 10 kat artabilmektedir. Bir hata ne kadar erken tanımlanır ve düzeltilirse kuruluş için o kadar az maliyetli olmaktadır (Braun).

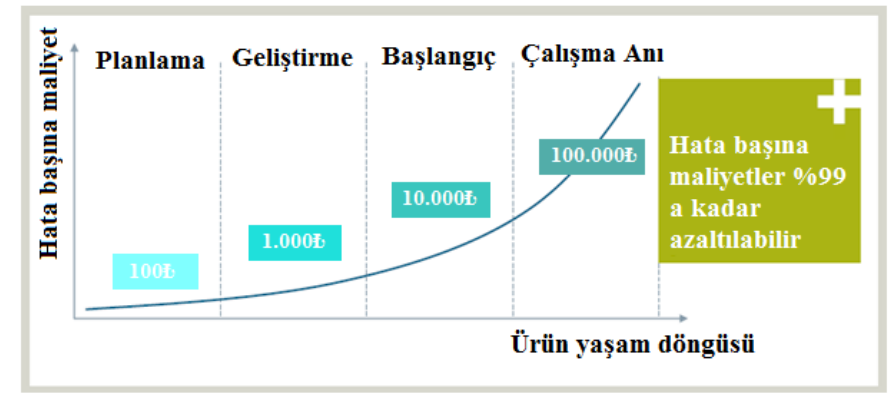

Şekil 1.2: Hataların süreçteki yerine göre düzeltme maliyeti

Makine tasarımı karmaşık bir süreçtir. Mekanik tasarım, elektrik ve kontrol yazılımı arasındaki etkileşim birçok organizasyonda ciddi sıkıntılara yol açmaktadır. Çoğu durumda, elektriksel tasarım ve yazılım geliştirme, mekanik tasarım tamamlanıncaya kadar başlayamamaktadır. Elektromekanik ürünler için tasarım yöntemlerinin çoğunun seri olması ve ilgili ekiplerin makine entegrasyonu öncesinde optimum etkileşiminin daha az olması sorun oluşturmaktadır. Bir makinenin gelişiminin ayrı bölümlerini (mekanik, elektrik, şemalar ve PLC yazılımı) gerçekleştirmek için birçok dijital araç vardır. Ancak bu disiplinleri tek bir işlev gören dijital prototipte birleştirmek mümkün olmamıştır. $\mathrm{Bu}$ da kavramları test etmeyi ve alternatifleri değerlendirmeyi zorlaştırmaktadır. Ayrıca, ilk derleme sürekli bir ayarlama, tekrar test ve hata ayıklama turu haline geldiği için gecikmeler yaygın olarak yaşanmaktadır.

Günümüzde, müşteri gereksinimlerini toplama ve ayrıntılı mühendisliğe başlama aşamaları arasında bir darboğaz vardır. Birçok büyük şirkette tasarlanan hat montajı ve devreye alma arasında doğrudan bir bağlantı yoktur. $\mathrm{Bu}$ da sistemi ortaya 
koyma ve devreye almaya kadar tüm gereksinimlerin karşılanamaması sorununu ortaya çıkarmaktadır (Blaschke, 2017). Bu darboğaz, hareket kontrol yazılımı ve elektrik tasarımı gibi aşamaların başlamasından önce sağlam geometrik kavramlara ihtiyaç duyulduğu için, müşterilerin çoğu için ciddi bir problem teşkil eder. Müşteriler sadece işin sonucundaki sistemle ilgilenirken makine imalatçıları tasarımda aynı işi yapabilecek onlarca farklı mantık ve ekipman arasından optimumunu seçmek için çabalar.

Sonuçta, düşünsel tasarım ayrıntısız haliyle bir mekanik tasarım haline getirilir. Ancak burada da sadece çarpışma gibi basit durumların testi yapılabilir. İmalat sonrasında da otomasyon hattının tüm denemeleri gerçek sistem üzerinde yapıldığında hattın maksimum hızlarının denenmesinin sisteme zarar verme riski olduğu için bazen denenemez ve gerçekte maksimum hızlardan daha düşük hızlarda çalışma yapılmak zorunda kalınabilir.

\subsection{Otomasyon Sistemlerinin Sanal Optimizasyonunun Sağlayacağı Faydalar}

Otomasyon hatlarının devreye alınmasında ortaya çıkan sorunlara çözüm olarak sistemin optimizasyonunun yapılabildiği sanal devreye alma; devreye alma sürecinde maliyet ve zaman verimliliğini getiren ve pazara sunma süresini kısaltan bir tekniğin gerekliliğine bir cevap olarak ortaya çıkmıştır (Herbus, K., Ociepka, P., \& Gwiazda, A., 2017). Bu sorunların ortadan kaldırılması için eşgüdümlü çalışılmalıdır. Makinenin dijital ikizi daha önceden oluşturulup optimizasyonlar bu dijital ikiz üzerinde yapıldığında gerçek makinenin devreye alınması da sanal devreye alma sayesinde çok daha kısa olacaktır. Aralarında birçok köklü firmanın da olduğu bazı firmalar bu şekilde yazılımlar1; sistem tasarımından üretimine, üretiminden kullanıma, müşteri istekleri ve ürün değişimine uygun hale getirmeye kadar birçok aşamada kullanmaktadırlar.

Önde gelen tesis ve proses otomasyonu firması, kozmetik endüstrisine esnek paketleme makineleri geliştirmek için bu şekilde yazılımlar kullanarak verimliliğini arttırmıştır. Farklı disiplinlerden mühendislerin aynı anda projeler üzerinde çalışmasını sağlayarak geliştirme süresini yüzde 30'a kadar düşürdüğünü iddia etmiştir. Yazılımlar, dijital bir ikiz makine veya sistem oluşturmasına ve sanal olarak devreye almasına olanak tanır. Makine modeli ayrıca tüm uygulamanın işlevselliğini test etmek için gerçek makine kontrolüne bağlanır. $\mathrm{Bu}$ özellikler, mekatronik mühendislerinin gerçek makinenin devreye alınmasını büyük ölçüde hızlandırmasını sağlar (Blaschke, 2017).

$\mathrm{Bu}$ araştırmalar sonucunda bu çalışmada karmaşık yapıdaki otomasyon hatlarının oluşturulması sürecindeki hataları azaltmak amaçlanmış ve bu tür sistemlerde üretilecek hattın üretim ve kurulumunu kapsayan tüm süreç optimize edilmiştir.

\section{Materyal ve Metot}

Bu çalışmada Şekil 2.1'deki örnek bir şişe dolum tesisinin kapak takma istasyonu tasarlanarak optimizasyon adımları bu sistem üzerinde denenmiştir. Yapılacak optimizasyon adımları ile bu otomasyon hattının tasarımdaki iyileştirmeleri ve her bir optimizasyonun hattın çevrim süresine etkisi incelenmiştir. Hat üzerinde cam gövdeli şişelerin kapağı takılarak diğer istasyonlara doğru $700 \mathrm{~mm}$ lik bir konveyör üzerinden akmas1 sağlanacak şekilde tasarım yapılmıştır. Kapak takma işlemi 80mm stroklu pnömatik silindir ile bastırılarak yapılmaktadır. Stroğun kapak boyundan büyük seçilmesinin sebebi istasyonun farklı boylardaki şişelere kapak takmaya adapte olabilmesini sağlamaktır. İncelemeler sonucunda sisteme $500 \mathrm{~mm}$ lik lineer eksen eklenerek kapak takma işleminin konveyör akarken yapılacak şekilde tasarım güncellenmiştir. Şişeler $40 \mathrm{~mm}$ çapında silindirik yapıda $67 \mathrm{~mm}$ boyunda ve $40 \mathrm{gr}$ ağırlığındadır. Şişelerin algılama işlemi cisimden yansımalı optik sensör ile yapılmıştır.

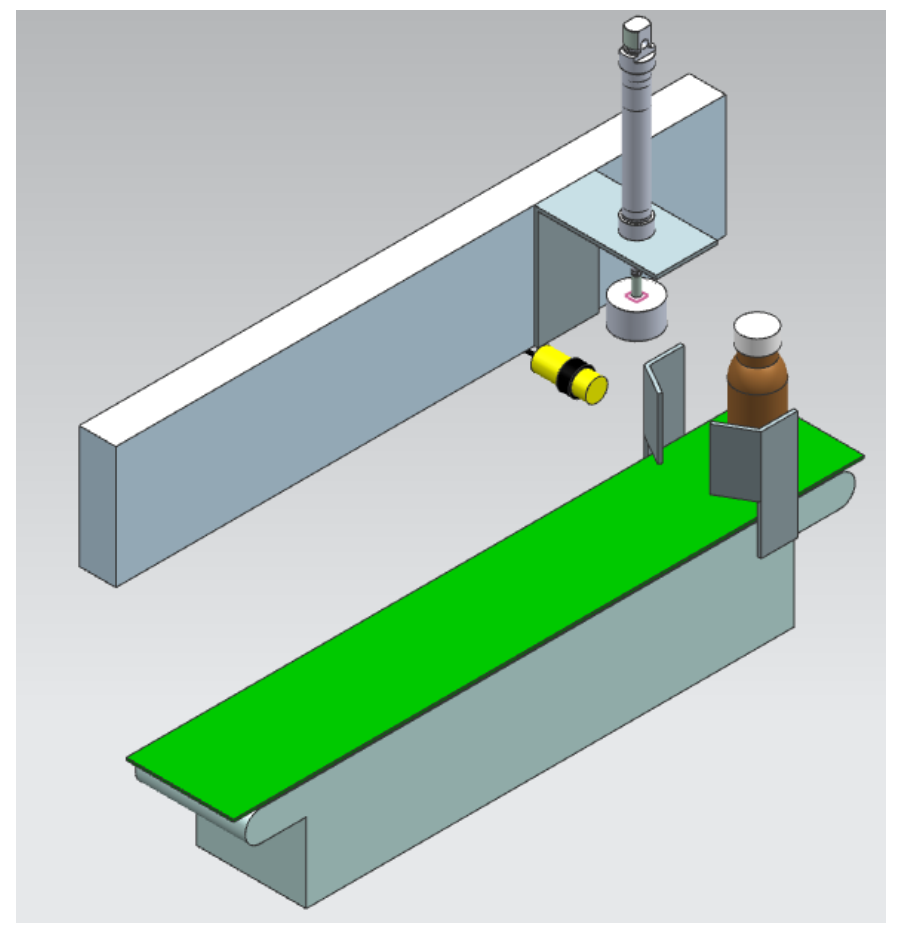

Şekil 2.1: Kullanılan Örnek Sistem

Sistemde şişeler görünen konveyör bandın girişinden beslenerek sensöre kadar gelmekte sensör şişeyi gördüğünde kapak takma silindiri aşağı inip yukarı çıkarak kapağı bastırarak takmakta ve sonra şişe bantta diğer istasyonlara doğru akmaya devam etmektedir. Optimizasyonlar sanal ortamda yapılacağından sistemde işlenen parçaların yerçekimi, sürtünme, ağırlık gibi fiziksel büyüklüklerine göre değişimleri gösteren yenilikçi bir tasarım programı kullanılmıştır.

\subsection{Algoritmanın Optimizasyonu}

Sistemin akış senaryosu optimize edilerek örnek hattın çevrim süresinin ne kadar azaltılabileceği araştırılmıştır. Sistem senaryosu parametrelerin ortalama değerlerinde denenerek sistemin mekanik hataları gözlemlenmiş ve sistemin tasarımsal optimizasyonu yapılmıştır. Bu sayede sistemin farklı zamanlarda ortaya çıkabilecek hatalarının giderilmeden devreye alma sürecine gelindiğinde ne kadar zarar ortaya çıkarabileceği de araştırılmıştır.

Örnek sistemde devreye alma işlemi Şekil 2.2'deki algoritmaya göre yapılmıştır. Hattın sıralı işlemleri, kullanılan yazılım ile simülasyonu yapılarak hattın akış senaryosuna uygun simüle edilmesi sağlanmıştır. $\mathrm{Bu}$ sayede sistemin konsept tasarımı üzerinde tüm detaylar düşünülüp gerçek otomasyon yazılımına hazır hale getirilmiştir. Sistemin mekanik ve sensör vb. elektronik donanımları montajı sonrası devreye alma için gerçek sistem başında kontrol yazılımı için harcanması gereken süreç kısaltılarak devreye alma süresi azaltılmıştır. Ayrıca bu akış belirlenirken sabit olması planlanan kapak kapama silindirinin bir kayar eksen üzerinde çalışmasının çevrim 
sürecinin azaltacağı görüldüğü için mekanik tasarımın optimizasyonuna da etki etmiştir.

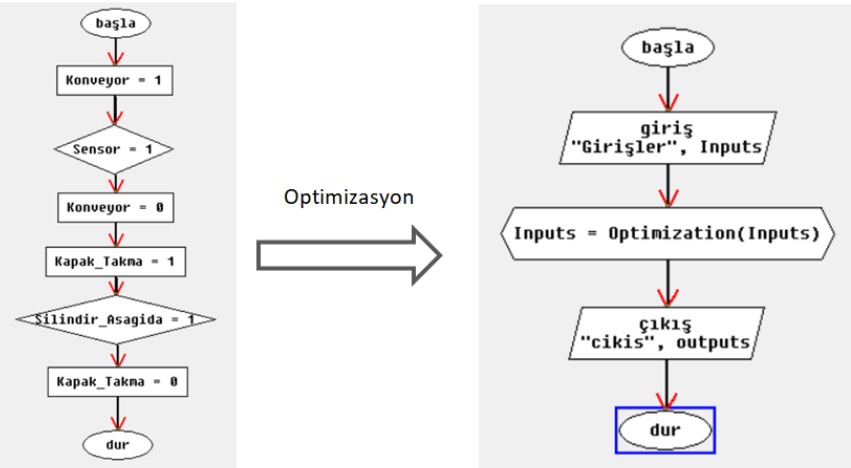

Şekil 2.2 Optimizasyon Öncesi ve Sonrası Algoritma

Başlangıç algoritmasına göre sistem ortalama bir hızda çalıştırıldığında konveyör banttaki şişenin kapatma silindiri altına gelmesi için gereken süre $0.5 \mathrm{~s}$, DC motor ile tahrik edilen konveyör bantın durma süresi $0.5 \mathrm{~s}$, silindir pistonunun aşağı için süresi 1s, Silindir pistonunun yukarı çıkış süresi 1s'dir. Yani sistemin çevrim süresi $3 \mathrm{~s}$ olarak ölçülmüştür. $\mathrm{Bu}$ ölçüm sonrasında çevrim süresini kısaltmak için kapak kapatma işleminin bant hareket ederken yapılmasının mümkün olup olmayacağı test edilmiştir. $\mathrm{Bu}$ testlere göre sistemin algoritması optimize edilmiştir.

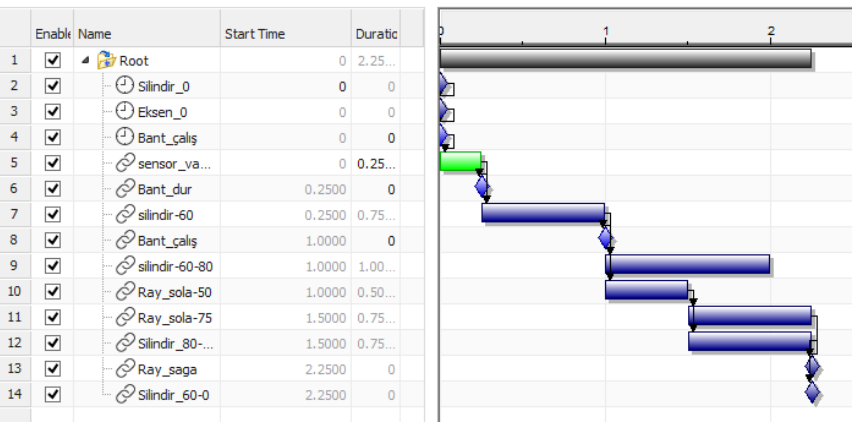

Şekil 2.3 Optimizasyonu yapılmış işlem sırasının programdaki gösterimi

\subsection{Konveyör Hızının Optimizasyonu}

Örnek sistem üzerinde konveyör motor hızı parametresi değiştirilerek sistemin optimizasyonu yapılmış ve sistemin verimliliği üzerindeki etkisi gözlemlenmiştir.
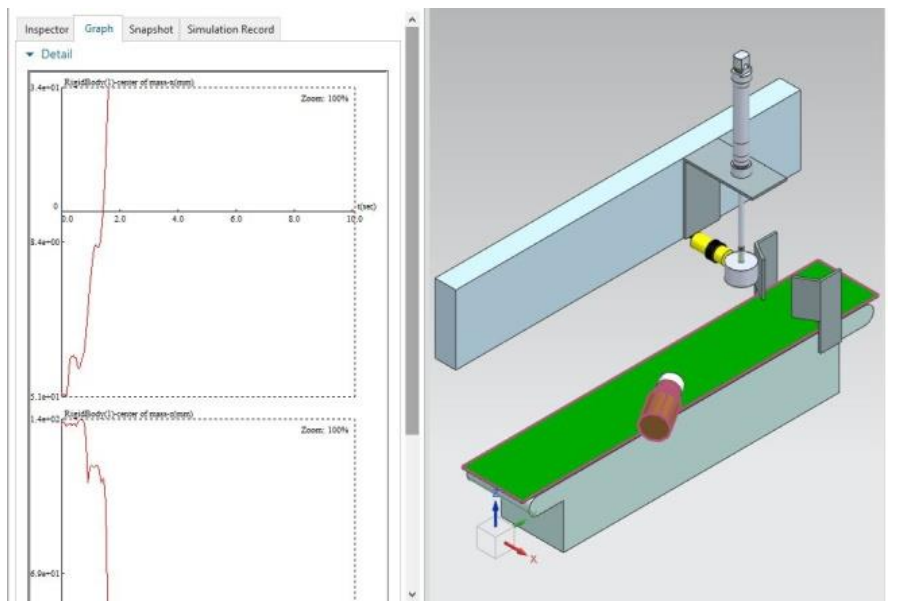

Şekil 2.4 (a). Motor hızı optimize edilmeden önce şişenin $Y$ ve $Z$ eksenindeki hareketleri
İlk olarak sistemde konveyörün ilerleme hızı şişenin düşmeyeceği garanti hı maksimum $150 \mathrm{~mm} / \mathrm{s}$ olarak düşünülmüştür. Ancak verimliliği arttırmak adına konveyör bant hızı yüksek hızlarda denenmiştir. $210 \mathrm{~mm} / \mathrm{s}$ akış hızında üzerindeki şişenin normalde doğrusal bir değişim göstermesi gereken Y ekseni ve değişim göstermemesi gereken $\mathrm{Z}$ ekseni grafiği incelenmiştir. $210 \mathrm{~mm} / \mathrm{s}$ de şişenin bant hareketi esnasında düştüğü gözlemlenmiştir. $Y$ ve $Z$ grafiği kabul edilebilir bir oranda az değişim gösterene kadar bant hızı düşürülerek denemeler devam etmiştir.

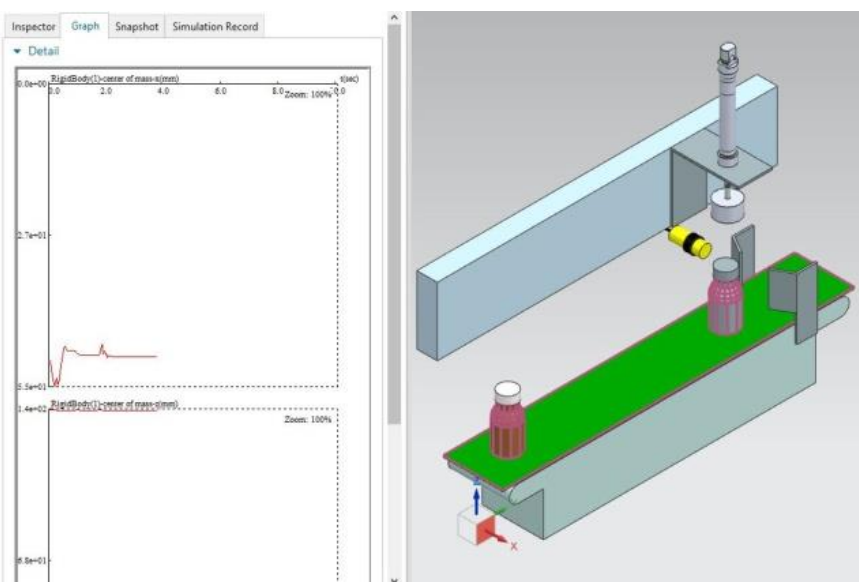

Şekil 2.4.(b) Motor hızı optimizasyonuna bağlı şişenin $Y$ ve $Z$ eksenindeki hareketleri

\subsection{Silindir Hızının Optimizasyonu}

Sistemde en kısa şişenin kapağını kapatmak için silindirin 80 stroğunun tamamı kullanılacak şekilde testler yapılmıştır. Ancak çevrim süresini düşürmek için silindirin şişe boyuna uygun pozisyonda beklemesini sağlayacak sensörler sisteme eklenmiş ve bu sayede silindirin kapağı takmak için aşağı iniş çıkış süresi kısaltılmıştır.
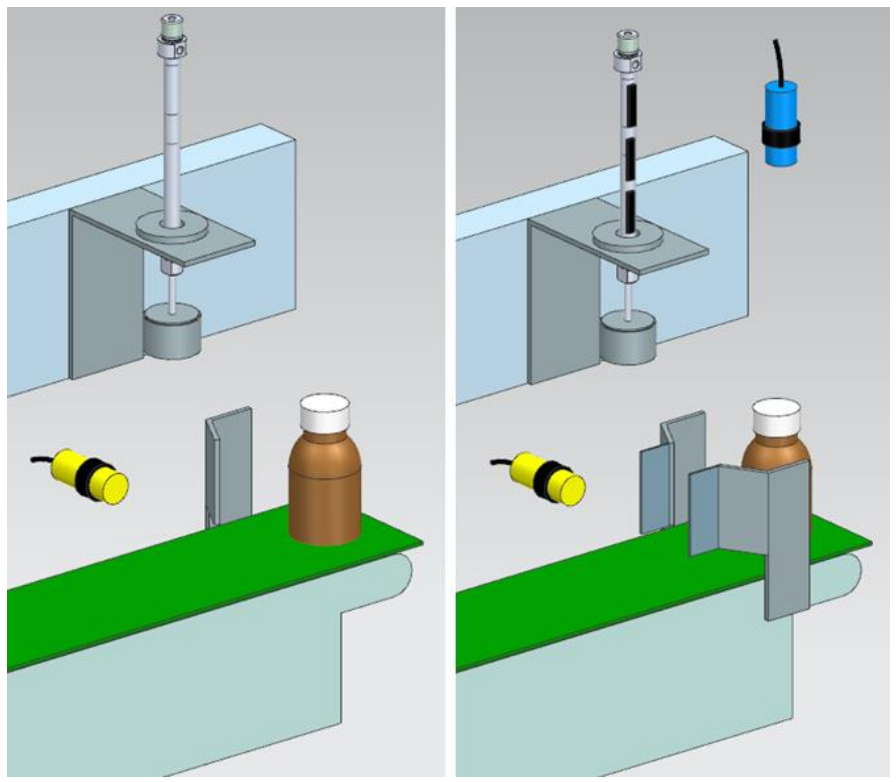

Şekil 2.5:Optimizasyon öncesi(a) ve sonrası(b) silindir

\subsection{Mekanik Tasarımın Optimizasyonu}

Sistemde hız, senaryo gibi değişikliklerin haricinde mekanik tasarımı üzerinde optimizasyon yapıldı. Örnek sistemde 
başlangıçta kapak takan silindirin sabit olması planlanmıştır. Ancak sistem algoritması optimizasyonunda kapağın şişe akışı esnasında takılmasının çevrim süresini kısalttığından sisteme bir lineer eksen eklenmiştir. Şişe boyunun ölçülmesi için eklenen analog sensörü tutacak plakalar eklenmesi gerekmektedir. Diğer bir yandan başlangıçta şişenin bandın ortasından gitmesi için başlangiçta tek kanat yeterli görülmüştür. Ancak sisteme hareket verildiğinde tek kanada çarparak şişenin diğer yönde fazla kaydığı ve düzeltilmesi gerektiği anlaşılmıştır. Sonucunda karşı tarafina da bir yönlendirme kanadı eklenmiştir. Bu düzeltme sonrasında şişeler kanat arasına sıkışıp devrilmeye başlamıştır. $\mathrm{Bu}$ sorun kanatlar arasındaki geçiş boşluğunun arttırılmasıyla düzeltilmiştir. Şişelerin ortadan değil yanlardan gelme durumu gözlemlendiğinde ise şişelerin kanatların ucuna sürtünerek döndüğü ve sonrasında merkezinin bozulduğu görülmüştür. $\mathrm{Bu}$ durumu düzeltmek için ise kanatların ucuna konveyöre paralel uzatmalar eklenmiştir. Mekanik olarak sistem tasarımı Şekil 2.6 da verilen işlem basamakları ile son halini almıştır. Bunun haricinde sistemin optimum çalışma hızına ve sensör algılama sonrasında bandın durma süresine göre; sensör, silindir, kayar eksen yerleşimleri de optimize edilmiştir.
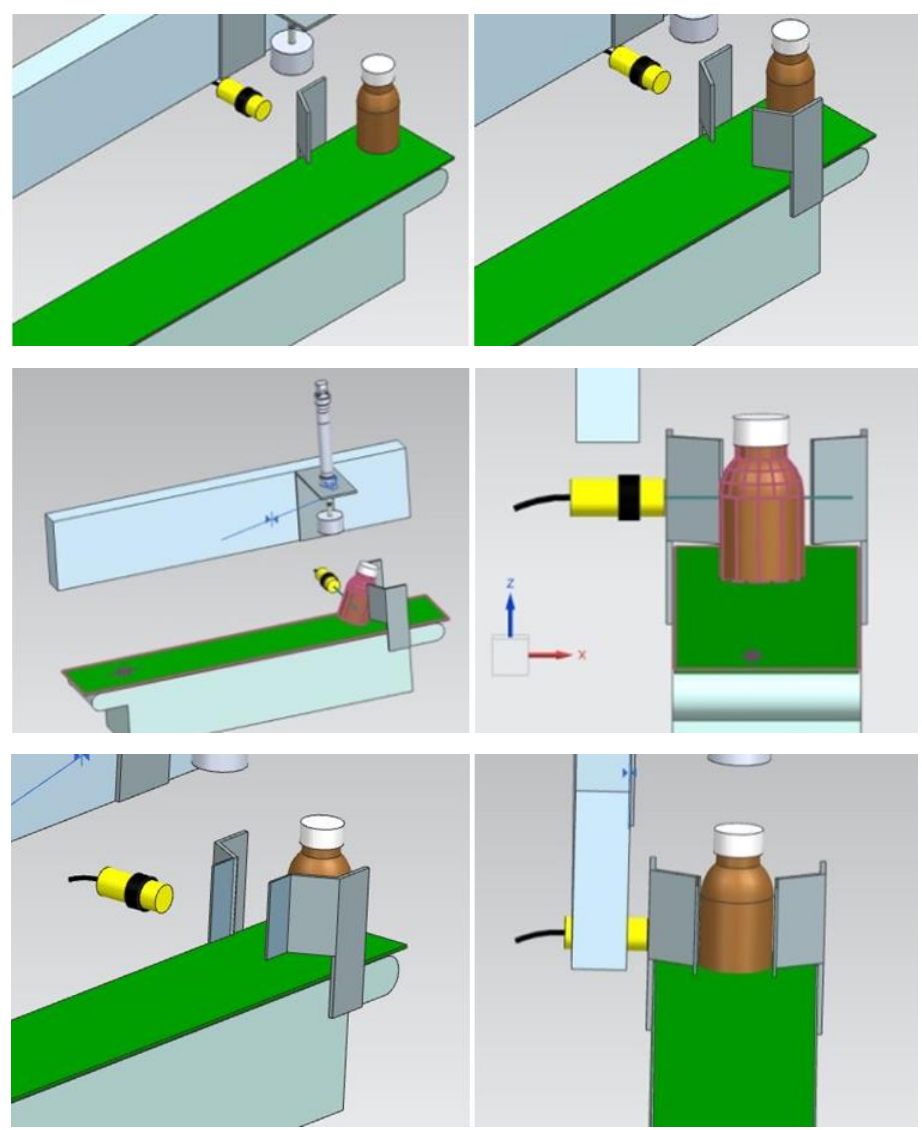

Şekil 2.6: Mekanik tasarım optimizasyon aşamaları

\section{Araştırma Sonuçları ve Tartışma}

Sanal testler sonucunda; kapak takma silindirinin kayar bir eksen üzerinde hareket ederken kapağın takılmasının mümkün olduğu görülmüştür. Sistem akışının optimizasyonu sonucu başlangıçta 3 saniye olan çevrim süresi sadece akışın optimizasyonu sayesinde 2,5 saniyeye düşürülmüştür.

Konveyör bant hızı 150mm/s iken hızlandırılarak $180 \mathrm{~mm} / \mathrm{s}$ hız optimum çalışma hızı olarak ayarlanmıştır. $\mathrm{Bu}$ sayede sistemin çevrim süresi 2,5 s den 2,4 saniyeye düşürülmüştür.

e-ISSN: 2148-2683
Kapak takma silindirinin iniş ve çıkış süresi 1s iken sistemin dijital ikizi üzerinden 0,8 s olacak şekilde optimize edilmiştir. $\mathrm{Bu}$ sayede sistemin çevrim süresi 2,4s den 2,1s'ye düşürülmüştür.

Sistemin daha tasarım sürecinde optimizasyonunu yapmak; sistemi oluşturan parçaların eksikliğinden ve mekanik yerleşiminden doğabilecek problemleri daha imalat yapmadan görüp, çözmeye yardımcı olmuştur. Sistem 1 ayda optimum şekilde tasarlanmıştır. Geleneksel yönteme göre 1 ay daha erken devreye alınması sağlanmıştır. $\mathrm{Bu}$ sayede sonradan ortaya çıkabilecek işçilik ve yanlış mekanik donanımdan doğabilecek ek maliyetler engellenmiştir.

\subsection{Maliyetlere etkisi}

Yapılan optimizasyonların sistemin çevrim süresini önemli ölçüde düşürebileceği ve buna bağlı olarak üretim kapasitesinin artacağı sonucuna varılmıştır. Ayrıca tasarımda yapılan optimizasyonların yapılmadan geleneksel yöntemlerle sistem devreye alınıp sonradan düzeltmelerin yapılmasının bu sistem üzerinde 1 ay ek süre ihtiyacı doğuracağı varsayılmış ve bu varsayım üzerinden sistemin 1 aylık ne kadarlık ek kazanç elde edilmesine yaradığı da gösterilmiştir. Örnek hat tasarımı üzerinde yapılan iyileştirmelerin sistemin devreye alınma süreci ve çevrim süresine bağlı olarak yıllık üretim miktarına etkisi Şekil 3.1'de gösterilmiştir.

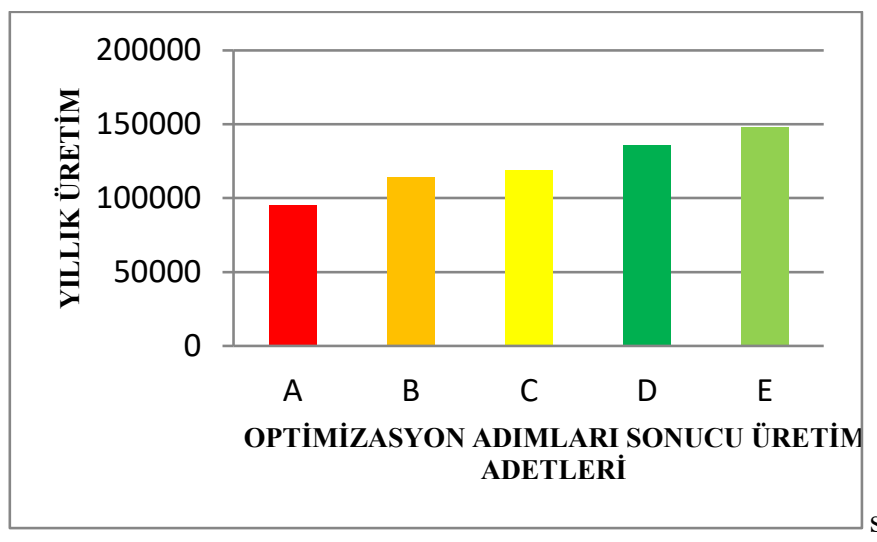

Şekil 3.1 Yapılan optimizasyonların yıllık üretim miktarına etkisi

\subsection{Tasarım sürecine etkisi}

Genel tasarım, mekanik bileşenler ve aynı anda programlama üzerinde çalışarak sistemin ortaya çıkış süresi önemli ölçüde azaltılabilmektedir. Bu örnek projede tasarım süreci 2 ayda tamamlanmıştır. Benzer bir sistemin geleneksel yöntemlerle devreye alınıp üzerindeki hataların giderilmesiyle tam olarak ortaya çıkarılması 3 ay gibi bir süre alabilmektedir. Dolayısıyla sistem tasarımı ve montajı için gereken sürenin $\% 30$ kadar indirilmesi sağlanmıştır. Makine ve tüm bileşenleri tamamen sanal ortamlarda tasarlandığından, makine ve bileşen davranışını simüle etmek ve tek tek bileşenlerin birlikte çalışabilirliğini test etmek için dijital ikizleri kullanmak mümkün olmuştur. Çarpışmalar, devrilmeler bilgisayar ortamında herhangi bir hasara neden olmadan sadece bilgisayarda meydana geldiğinden rahatlıkla ilk denemeler yapılabilmiştir.

$\mathrm{Bu}$ yeni yöntemle sistemin dijital ikizini kullanarak, tasarımcıların, mühendislerin ve programcıların aynı proje üzerinde aynı anda çalışması ve sürekli fikir alışverişi yapması ve deneyimlerin paylaşı1ması mümkün olabilmektedir. Sistem üzerinde hem mekanik ekipmanlar belirlenmiş, hem sensör, motor vb. elektronik ekipman seçimleri yapılmış hem de 
yazılıma yardımcı olacak işlem sıralarıyla ilgili optimizasyon da sağlanmıştır.

Sistemin tasarım süreci ise yapılan yöntem ile iki ayda tamamlanmıştır. $\mathrm{Bu}$ tasarım optimizasyon adımları gerçekleştirilmeden yapılıp hatalar sistem gerçekten devreye alındıktan sonra düzeltilmeye çalışılsaydı üç aylık bir süreçte tamamlanabileceği öngörülürse tasarım sürecinde de en az \%30 luk bir iyileştirme sağlayacağı düşünülmektedir.

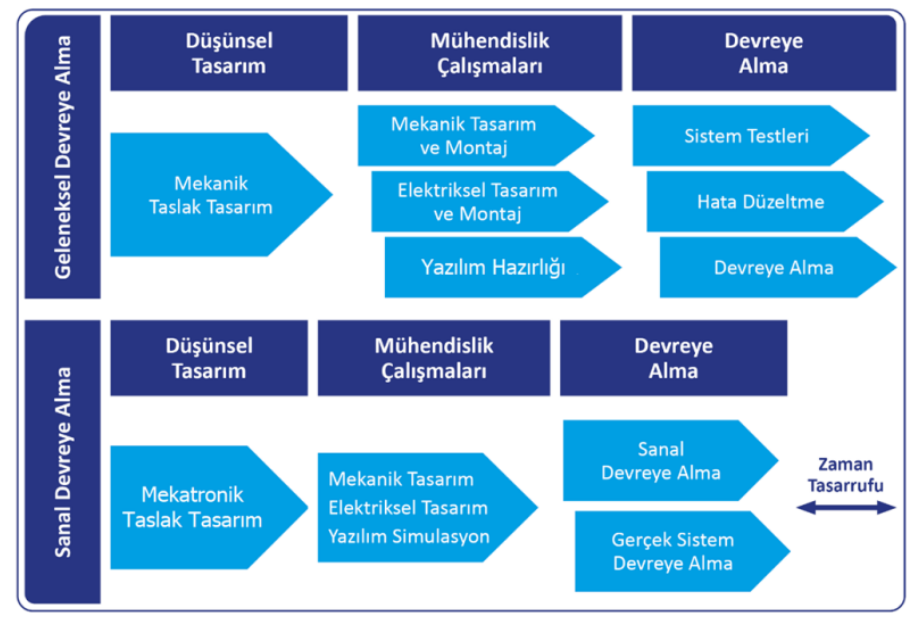

Şekil 3.2: Otomasyon hatlarını devreye almada sanal optimizasyonun geleneksel devreye almadan fark

$\mathrm{Bu}$ çalışma otomasyon hatlarının tasarımda ve denenmesinde sanal devreye alma konusunun işletmelerin veya üreticilerin verimliliğine katkısı örnek üzerinden araştırılmış gösterilmiştir. Günümüz dijital teknolojilerinden sanal devreye alma, makinelerin dijital ikizi gibi konuların otomasyon hattı imalatçılarına sağlayabileceği faydalar ortaya konmuştur. Hatların programlanıp denenmesinin sağlanabileceği yazılımlarda tasarımlar üzerinde denenebilecek şekilde tasarım konusuna yenilikçi bir bakış açısı kazandırabilecektir.

\section{Sonuç}

Tüm araştırmalar ve çalışma sonucunda otomasyon hatlarının sanal ortamda optimizasyonunun sistem tasarım sürecine, maliyetlere, müşteriye sunuma olumlu etkileri görülmüştür.

Yapılan çalışmalara göre otomasyon hatlarında sanal devreye alma işlemi yapılarak sistemin algoritması, bazı parametreleri ve mekatronik tasarımı optimize edilerek sistemin çevrim süreci 3s'den 2,1s'ye düşürülerek örnek bir hat üzerinde yapılan basit optimizasyon adımlarıyla sistemde \%30 luk bir verimlilik artışı sağlayabileceği gözlemlenmiştir.

\section{Teşekkür}

Bu çalışma FYL-2020-10097 numaralı Marmara Üniversitesi Bilimsel Araştırma Projeleri Birimi (BAPKO) Lisansüstü Tez Projesi kapsamında desteklenmiştir.

\section{Kaynakça}

Blaschke, S. (2017). Leading plant and process automation firm uses Mechatronics Concept Designer to develop flexible packaging machines for the cosmetics industry. Siemens.

Blaschke, S. (2017). Mechatronics Concept Designer offers huge time savings in the design of machines and systems. 08 18, 2020 tarihinde https://www.plm.automation.siemens.com/global/en/ourstory/customers/festo/17518/. adresinden alind1

Braun, V. (tarih yok). www.cadenas.de. 2020 tarihinde alınd

Çilek, A. (2005). PLC ile Endüstriyel Otomasyon Uygulaması. Yüksek Lisans Tezi. Gazi Ünv. Fen Bilimleri Enst., Ankara, Türkiye.

Groover, M. (2001). Automation Production Systems and Computer-Integrated Manufacturing. Pearson Education: New York.

Henning, K. (2013). Recommendations for implementing the strategic initiative Industrie 4.0. Plattform Industrie 4.0.

Herbus, K., Ociepka, P., \& Gwiazda, A. (2017). Designing of a technological line in the context of controlling with the use of integration of the virtual controller with the mechatronics concept designer module of the PLM Siemens NX software. IOP Conference Series: Materials Science and Engineering, 227-235.

Karcı, H. (2001). Tasarımda Kontrol Tekniğinin Yönlendirici Etkisi. 2. Ulusal Hidrolik Pnömatik Kongresi (s. 73-80). İzmir: MMO.

Puntel-Schmidt, P., \& Fay, A. (2015). Levels of detail and appropriate model types for virtual commissioning in manufacturing engineering. IFAC-PapersOnLine, 48(1), 922-927.

Stock, T., \& Seliger, G. (2016). Opportunities of Sustainable Manufacturing in Industry 4.0. Procedia CIRP, 536-541. 